\title{
Enhanced neural modulations during BMI experiments: control
} perspective

\author{
Miriam Zacksenhouse*1, Koren Beiser ${ }^{1}$, Joseph E O'Doherty², \\ Mikhail A Lebedev ${ }^{3}$ and Miguel AL Nicolelis ${ }^{3}$
}

\author{
Address: ${ }^{1}$ Faculty of mechanical Engineering, Technion, Haifa, Israel, ${ }^{2}$ Department of Biomedical Engineering, Duke University, Durham, NC, \\ 27710, USA and ${ }^{3}$ Department of Neurobiology, Center for Neuro-engineering, Duke University, Durham, NC, 27710, USA \\ Email: Miriam Zacksenhouse* - mermz@tx.technion.ac.il \\ * Corresponding author
}

from Eighteenth Annual Computational Neuroscience Meeting: CNS*2009

Berlin, Germany. 18-23 July 2009

Published: 13 July 2009

BMC Neuroscience 2009, I0(Suppl I):P342 doi:I0.1186/I47I-2202-10-SI-P342

This abstract is available from: http://www.biomedcentral.com/I47|-2202/I0/SI/P342

(c) 2009 Zacksenhouse et al; licensee BioMed Central Ltd.

\section{Background}

Recent experiments with brain-machine-interfaces (BMIs) indicate that the extent of neural modulations increases abruptly upon starting to operate the interface. In contrast, neural modulations that are correlated with the profile of the trajectory remain relatively unchanged. Furthermore, the enhanced modulations subside with further training, mirroring the trend in task performance, which degraded when starting to operate the interface and improved gradually with training [1]. The interpretation of the enhanced modulations and the characterization of the signals that they may encode are of major interest for understanding human motor learning and control, the improvement of future BMIs and the development of effective rehabilitation programs.

\section{Results: experimental}

Here we investigate the hypothesis that the enhanced modulations reflect internal representation of estimation errors, and the consequent correction or explorative commands. This hypothesis is supported by further BMI experiments involving center-out movements to randomly located targets on a fixed circle. These BMI experiments facilitate the evaluation of neural modulations (across different reaching movements) at a fixed delay after target appearance. The analysis demonstrates that the relative variance of neural modulations is low during the inter-trials, increases during the initial part of the move- ment - after target onset - and remains flat in the later part of the movement. When operating the BMI, the relative variance of the neural modulations increases to higher levels and the trials extend longer.

\section{Results: modeling and simulations}

The observed enhancement in neural modulations may be interpreted in the context of three computational motor control models: (i) hybrid control, (ii) optimal control, and (iii) dual control. The optimal control model is investigated in detail by simulating neural populations that are tuned to both the open-loop and close-loop estimation and control signals. Simulation results demonstrate that this model can explain the observed enhancement in the neural modulations when switching from skilled to BMI operation. Both the modeling and experimental results support the hypothesis that the enhanced neural modulations reflect error processing and suggest that they may be used to improve the operation of BMIs.

\section{Acknowledgements}

This research was supported by the Ashkenazy Handicap Research Fund for $M Z$ and grants from DARPA, the James S. McDonnel Foundation, NIH and NSF to MALN.

\section{References}

I. Zacksenhouse M, Lebedev MA, Carmena JM, O'Doherty JE, Henriquez CS, Nicolelis MAL: Cortical modulations increase during 
early sessions with Brain-Machine Interface. PLOS-ONE 2007, 2:e619.

Publish with Biomed Central and every scientist can read your work free of charge

"BioMed Central will be the most significant development for disseminating the results of biomedical research in our lifetime. " Sir Paul Nurse, Cancer Research UK

Your research papers will be:

- available free of charge to the entire biomedical community

- peer reviewed and published immediately upon acceptance

- cited in PubMed and archived on PubMed Central

- yours - you keep the copyright 